\title{
A produção de documentários através do DOCTV
}

Verena Carla Pereira

\section{Resumo:}

Este artigo irá tratar do Programa de Fomento à Produção e Teledifusão do Documentário Brasileiro, o DOCTV, que é hoje o maior programa de produção de documentários através do apoio estatal no Brasil. Iremos abordar seus aspectos estéticos, autorais, econômicos, de exibição e de distribuição. Além disso, iremos analisar as temáticas dos filmes desenvolvidos dentro desse projeto e como está sendo constituída a rede de exibição do Programa. A pesquisa de mestrado do qual ele se origina insere-se dentro das atividades atualmente desenvolvidas pelo Cepecidoc (Centro de Pesquisas do Cinema Documentário do Instituto de Artes da Unicamp).

\section{Palavras Chave:}

documentário; DOCTV; cinema; estado.

\begin{abstract}
:
This article deals with the Programa de Fomento à Produção e Teledifusão do Documentário Brasileiro (DOCTV), which is, nowadays, the major State sponsored program of documentary production in Brazil. The article analyzes the program's aesthetical, authorial, economical, exhibitional and distributional aspects. Besides, the paper also analyzes the movies' themes developed in this project and how the Program exhibitional network is built. This research project is connected with the activities developed currently by Cepecidoc (Centro de Pesquisas do Cinema Documentário do Instituto de Artes da Unicamp).
\end{abstract}

\section{Keywords:}

documentary; DOCTV; cinema; state.

\section{Breve histórico do apoio estatal ao documentário}

O Programa de Fomento à Produção e Teledifusão do Documentário Brasileiro (DOCTV) foi criado visando à produção de documentários utilizando o apoio estatal. A iniciativa de fomentar a produção audiovisual através do apoio do Estado pode ser considerada uma tradição nas políticas públicas de apoio à cultura no Brasil. Começando nas décadas de 1930 e 1940, quando do advento do cinema sonoro, o documentário no Brasil articulava-se basicamente em torno do Instituto Nacional de Cinema Educativo (INCE), que foi criado em 1936 a partir de uma proposta de Roquette Pinto. Dentro do INCE, uma das figuras de maior destaque foi o cineasta Humberto Mauro, que produziu um valioso acervo de filmes através do INCE.

O incentivo à produção cinematográfica vinculada à educação privilegiou a produção do documentário. Nos primeiros anos da década de 40, ocorreu uma redução na produção de documentários pelo INCE em virtude da guerra. Além do INCE, o Departamento de Imprensa e Propaganda (DIP) getulista e o Serviço de Informação do Ministério da Agricultura também foram órgãos públicos federais que se destacaram na produção de documentários no Brasil dos anos 30 e 40. No cenário nacional, tal tradição de produção documentária ligada ao apoio estatal também pode ser observada no período da Embrafilme (extinta no governo Collor) e do Ministério da Cultura a partir da década de 90. Com a criação de Leis de Incentivo como 
a Lei Rouanet e a Lei do Audiovisual, mais uma vez o Estado passa a fomentar a produção cinematográfica nacional. Nesse contexto o governo federal criou também uma série de editais de incentivo a Cultura - entre eles, destacamos o edital que regulariza o DOCTV.

\section{O DOCTV}

O DOCTV teve sua primeira edição em 2003, quando foi firmado o convênio entre o Ministério da Cultura (Minc), a Fundação Padre Anchieta (FPA) / TV Cultura e a Associação Brasileira de Emissoras Públicas, Educativas e Culturais (ABEPEC). Esse convênio foi mantido durante as três primeiras edições do DOCTV. Até 2006, foram produzidas três edições do DOCTV no Brasil (foi fomentada também a edição Ibero Americana do Programa, da qual iremos tratar mais abaixo), gerando 115 documentários, 3.080 horas de programação e 2.310 inscrições. Esse último número é altamente significativo se comparado as 210 inscrições que o Minc recebeu em 2001 antes da criação do DOCTV.

Os principais objetivos do DOCTV, de acordo com o Programa de Editais de Fomento à Produção criado pelo Minc, são:

1. Promover a regionalização da produção de documentários;

2. Articular um circuito nacional de teledifusão através da rede pública de TV;

3. Propor um modelo de negócio que viabilize mercados regionais para o documentário;

4. Incentivar a parceria de produtores independentes com as TVs públicas;

5. Valorizar e promover a diversidade cultural brasileira ampliando o conhecimento das diferentes expressões regionais em todos os estados;

6. Dar oportunidade a um maior número de realizadores ao apresentar os talentos locais a outros estados brasileiros, gerando uma descentralização da produção do eixo Rio - São Paulo;

7. Criar núcleos de realizadores e produtores independentes nos estados.

A principal fonte de financiamento do DOCTV é o convênio firmado entre o Minc, através da Secretaria do Audiovisual (SAV) e a FPA. Os recursos foram articulados junto ao Fundo Nacional de Cultura. Além disso, as produções também recebem parte do financiamento por meio das TVs públicas participantes e das Secretarias Estaduais de Cultura. O número de documentários produzidos em cada Carteira Estadual do DOCTV depende dos seguintes dados: capacidade de investimentos da Secretaria do Audiovisual do Minc, que é responsável por $80 \%$ da verba para realização do filme; e a capacidade de contrapartida de cada TV pública, responsável pelo aporte de $20 \%$ do valor de cada documentário. Na primeira edição do DOCTV o orçamento oferecido para a realização do filme foi de 90 mil reais. Já no DOCTV II e III os contratos foram no valor de 100 mil reais.

Para a seleção do Programa, os candidatos devem indicar uma empresa produtora para atuar como responsável pela realização do projeto no contrato de co-produção. Assim, o candidato tem que lidar com outros três parceiros: o canal de TV, o Minc e uma produtora escolhida pelo autor do projeto. Após a assinatura do contrato de co-produção e o aporte da primeira parcela dos recursos financeiros, os projetos premiados têm obrigatoriamente que serem concluídos num prazo máximo de cento e cinqüenta dias. Os 
recursos de produção obedecem ao seguinte parcelamento:

- $20 \%$ na assinatura do contrato

- 40\% no início da etapa de filmagem

- 30\% no início da etapa de edição

- $10 \%$ na conclusão da etapa de finalização.

Uma vez realizados, tais documentários são veiculados em faixa de programação nacional, pelas TVs públicas participantes da Rede DOCTV, estabelecendo a regionalização da programação no campo público de televisão. Para estruturação da Rede DOCTV, foi criada uma instância de Coordenação Executiva, na TV Cultura de São Paulo. A parceria entre a TV pública e as seções estaduais da Associação Brasileira de Documentaristas (ABD) nas 27 unidades federativas gerou a implantação de Pólos Estaduais de Produção e Teledifusão.

A partir da segunda edição do DOCTV surgiu a iniciativa de Carteiras Especiais, formadas através da articulação de recursos financeiros pelos pólos estaduais junto à iniciativa privada e administrações públicas. Assim, os concursos estaduais podem selecionar mais projetos de documentários do que a edição nacional já garante e a instituição/empresa associada tem como garantida a visibilidade de sua marca na programação da TV pública participante da Carteira Especial. No Modelo de Negócio do DOCTV, a Carteira Especial é uma ação avançada que articula novos recursos para a produção de mais documentários. Executada dentro do mesmo modelo de gestão do DOCTV, a Carteira Especial constitui-se, contudo, numa iniciativa de autonomia local. Quando um Pólo Estadual (ou de um conjunto de Pólos Estaduais, quando se trata de uma Carteira Regional) decide organizar tal iniciativa, elabora-se um projeto que será analisado pelos parceiros potenciais no mercado local, tendo início assim as negociações.

Também a partir da segunda edição do DOCTV foram implantadas Ações de Formação para auxiliar os documentaristas na realização de seus filmes. Buscando um diálogo com a cultura audiovisual brasileira, o Programa gerou ações como: o aperfeiçoamento do Regulamento dos Concursos DOCTV e das condições de trabalho das Comissões Estaduais de Seleção; a introdução de Oficinas Estaduais para Formatação de Projetos e de seu Manual Didático; a realização da Oficina para Desenvolvimento de Projetos e a continuidade de seu debate nos Relatórios de Produção dos documentários; o Seminário DOCTV; e a consolidação de toda a experiência das Ações de Formação no projeto de publicação Cadernos DOCTV.

A iniciativa das Ações de Formação surgiu com a experiência da primeira edição do Programa. Notou-se que "o DOCTV não havia conseguido superar a armadilha da diversidade temática, igualando-se a uma série de concursos que elegem 'o melhor tema' e não a melhor proposta de relação com o tema, amadurecimento desejado aos Concursos DOCTV” (Balanço DOCTV). Assim, através das Ações de Formação buscou-se reformular o Regulamento dos Concursos Estaduais.

Além da co-produção e da teledifusão, o DOCTV prevê ações na área de distribuição nacional e internacional. A TV Cultura/ FPA, através da Cultura Marcas, desenvolveu junto à Coordenação Executiva do Programa DOCTV a sistemática de distribuição de seu conteúdo. A distribuição nacional de «homevideo», que é feita pela Editora e Distribuidora «Log On» em parceria com a Cultura Marcas, dá-se pela venda «on demand» via internet e distribuição de «packs». O recurso relativo ao Fundo DOCTV é reinvestido em ações do próprio Programa, buscando a auto-sustentabilidade. Destaca-se também a iniciativa do DOCTV junto a TV Escola, um Programa da Secretaria de Educação à Distância, do Ministério da Educação (MEC). Consiste num canal de televisão via satélite destinado à educação, com o objetivo de promover a capacitação, atualização e 
aperfeiçoamento dos professores da Rede Pública de Ensino Fundamental e Médio. Para a Carteira DOCTV Escola foram selecionados vinte e oito títulos entre a primeira e a segunda edição do Programa de acordo com os parâmetros estabelecidos pela Lei de Diretrizes e Bases da Educação, e pelos critérios manifestados pela TV Escola em sua primeira avaliação dos documentários do Programa.

As ações de distribuição internacional dão-se pela convergência do Programa DOCTV Brasil com os Programas «Brazilian TV Producers» - Programa da SAV junto ao Ministério de Desenvolvimento, Indústria e Comércio Exterior (MDIC), através da Agência de Promoção à Exportação do Produto Brasileiro (APEX), do Serviço Brasileiro de Apoio às Micro e Pequenas Empresas (SEBRAE) e da Associação Brasileira dos Produtores Independentes de Televisão (ABPITV) - e DOCTV Ibero América (DOCTV IB). O «Brazilian TV Producers» cria pontes entre o produto independente brasileiro e o circuito de feiras internacionais do mercado mundial de televisão. Já o DOCTV IB é um caminho para os mercados nacionais junto às TVs públicas que constituem a Rede DOCTV IB.

Tanto nacionalmente quanto internacionalmente, os documentários produzidos no DOCTV podem ser comercializados por todas as partes envolvidas no processo. Nas três primeiras edições do Programa, a receita gerada por título comercializado era distribuída entre autor $(12,5 \%)$, empresa produtora $(12,5 \%)$, TV pública (20\%) e Fundo DOCTV (55\%). Em suma:

O plano de trabalho do Programa DOCTV consiste na implantação de pólos estaduais de produção e teledifusão de documentários; na realização de oficinas de planejamento executivo oferecidas aos gestores dos pólos estaduais; na descentralização de recursos públicos por meio da realização de concursos estaduais para seleção de projetos; na realização de oficinas de formação associando a política pública ao debate estético do documentário; na produção de documentários em associação a produtoras e TVs públicas locais, estimulando a profissionalização do setor e a articulação de mercados regionais para o documentário; na distribuição desse conteúdo para todo o território nacional, por meio de geração via satélite, garantindo espaços às expressões regionais; e na exibição dos documentários pela programação em circuito nacional de teledifusão (Balanço DOCTV).

\section{DOCTV Ibero América}

O DOCTV encontrou sua expansão internacional, na realização do DOCTV Ibero América (DOCVT IB). O DOCTV IB é um Programa da «Conferencia das Autoridades Audiovisuales y Cinematográficas de Iberoamérica» (CAACI), que reúne autoridades audiovisuais nacionais, televisões públicas e associações de produtores independentes da Argentina, Chile, Uruguai, Brasil, Bolívia, Peru, Colômbia, Venezuela, Panamá, Costa Rica, Porto Rico, Cuba, México, Portugal e Espanha, sob a coordenação executiva da SAV / Minc do Brasil, «Secretaria Ejecutiva de la Cinematografia Iberoamericana» (SECI) e da «Fundación Del Nuevo Cine Latinoamericano» (FNCL). O Programa prevê um contrato de co-produção no valor de 100 mil dólares, dos quais 80 mil dólares são garantidos pelo Fundo DOCTV IB e os 20 mil dólares restantes são oferecidos pelo Pólo Nacional em forma de contrapartida, além da veiculação dos documentários no circuito ibero-americano de televisão. $\mathrm{O}$ aporte de responsabilidade do Pólo Nacional pode ser concretizado por recursos financeiros e/ou insumos de produção. A forma de composição deste aporte é definida pelo Pólo Nacional, tendo como base às exigências técnicas do projeto de documentário selecionado.

Os objetivos da versão Ibero americana do DOCTV são:

1. Estimular o intercâmbio cultural e econômico entre os povos ibero-americanos; 
2. Implantar políticas públicas integradas de fomento à produção e teledifusão de documentários nos países da região;

3. Difundir a produção dessas nações no mercado mundial.

Foram produzidos 13 documentários, selecionados entre 467 projetos inscritos (destes, cerca de 200 eram brasileiros). Uma vez realizados, os documentários de 52 minutos de duração foram exibidos nas 36 TVs do circuito ibero-americano de teledifusão. A rede foi articulada especialmente para o Programa e é composta pelas seguintes emissoras públicas:

- Argentina: «Canal Educativo del Ministerio de Educación, Ciencia y Tecnologia»;

- Chile: «Consejo Nacional de TV» (CNTV) e «Televisión Nacional de Chile» (TVN);

- Uruguai: TVEO Canal 5, TV «Ciudad» e Canal 10;

- Brasil: TV Cultura de São Paulo, TV Cultura do Amazonas, TV Cultura do Pará, TV Palmas, TV Educativa do Maranhão, TV Ceará, TV Universitária do Rio Grande do Norte, TV Universitária de Pernambuco, Instituto Zumbi dos Palmares, TV Aperipê, TV Educativa da Bahia, Radiobrás, TV Educativa Regional do Mato Grosso do Sul, Rede Minas, TV Educativa do Espírito Santo, Rede Brasil, Paraná Educativa, TV Cultura de Santa Catarina, TV Educativa do Rio Grande do Sul;

- Bolívia: «Televisión Boliviana» (TVB);

- Peru: «Instituto de Radio y Televisión del Peru» (IRTP);

- Colômbia: «Comisión Nacional de Televisión e Radio Televisión de Colombia» (RTVC);

- Venezuela: «Venezolana de Televisión» (VTV);

- Panamá: «Rádio e Televisión Educativa y Cultural de Panamá» (RTVE);

- Costa Rica: «Sistema Nacional de Radio y Televisión» (SINART);

- Porto Rico: «Corporación para la Difusión Pública»;

- Cuba: «Red de Exhibición del Instituto Cubano del Artes e Indústria Cinematográficas» (ICAIC);

- México: «Televisión Metropolitana, S.A»;

- Portugal: «Radio e Televisão de Portugal» (RTP);

- Espanha: «RadioTelevisión Española» (RTVE).

Esse circuito ibero-americano de teledifusão foi ampliado por TVs públicas de El Savador, Nicarágua, Honduras, Belize e Guatemala.

Com objetivos semelhantes aos do Programa realizado no Brasil, o DOCTV IB possui o mérito de conseguir unir em um único projeto audiovisual países geograficamente próximos, mas culturalmente distantes. Lançado em 2005, o Programa foi implantado em um período em que alguns desses países passavam por 
eleições presidenciais e, conseqüentemente, mudanças políticas. O modelo de negócio funciona de forma similar ao modelo brasileiro. Nesse caso, criou-se um Fundo DOCTV IB, viabilizado a partir de recursos oriundos do Brasil, Venezuela, México e Argentina. O fundo é responsável por financiar 80\% dos projetos, enquanto os $20 \%$ restantes ficam a cargo das TVs públicas de cada país (no caso de Portugal e Espanha o pólo nacional é responsável pelo aporte integral dos contratos de co-produção). Na primeira edição do DOCTV IB foram investimentos US\$ 1.877.530,00. O DOCTV IB gerou processos de implantação dos Programas DOCTV CPLP (da Comunidade de Países de Língua Portuguesa, com a participação de Angola, Brasil, Cabo Verde, Guiné-Bissau, Moçambique, Portugal, São Tomé e Príncipe e Timor Leste), do DOCTV México, DOCTV Colômbia e DOCTV Cinergia (formado por Guatemala, Honduras, El Salvador, Nicarágua, Costa Rica e Panamá).

\section{Análise temática dos documentários}

De acordo com os critérios de seleção, o Programa DOCTV visa projetos que busquem abordar manifestações e aspectos culturais do Brasil. Através de uma análise superficial dos temas trabalhados pelos documentários das três primeiras edições do DOCTV, notamos que a maioria dos filmes abordam temas como: movimentos populares (Exemplo: "Continente dos Viajantes", "Eretz Amazônia", "Mitos e Lendas no Reisado de Inhanhum" e "A Descoberta da Amazônia pelos Turcos Encantados"); biografias de personagens de destaque (Exemplo: "Imagem peninsular de Lêdo Ivo", "Cerimônias do Esquecimento", "Aldir Blanc - 2 Pra Lá, 2 Pra Cá", "Péricles Leal, o criador esquecido", "Hermógenes - Deus me livre de ser normal” e "Os negativos"), resgate e defesa de culturas ameaçadas (Exemplo: "Tumbalalá - Tupinambá Irmãos no Mundo", "Comunidade do Sutil", "A Próxima Refeição" e "Mapulawache: festa do pequi"), diversidade racial, cultural e social (Exemplo: "Preto Contra Branco", "Passagem" e "Ensolarado Byte") e episódios marcantes (Exemplo: "Tocantins - Rio Afogado" e "O homem do balão extravagante" ou "As tribulações de um paraense que quase voou").

Através desse breve levantamento podemos apontar duas questões. A primeira diz respeito ao enfoque geralmente apresentado nos documentários que tentam mostrar a diversidade brasileira. Entretanto, o que é claro no discurso de apresentação do DOCTV é a vontade de se criar um Programa que mostre a identidade brasileira através das diferenças. O DOCTV aposta na parceria entre a produção independente, as emissoras públicas, a iniciativa privada e o setor público no Brasil para a construção de um espaço de resistência na televisão que retomasse a ideologia do nacional popular vivido entre os anos 60 e 80 - tal projeto de construção identitária de um Brasil pode ser notado desde o Período Imperial. No DOCTV, diversas instâncias apontam para essa vontade política de se construir um projeto que dê oportunidade de mostrar as várias manifestações culturais do país, mas, ao mesmo tempo, criar o conceito de que essas manifestações pertencem a um só país. A consolidação desse empreendimento pode ser notada no texto do spot do DOCTV: "Imagine o Brasil/ Nós somos isso/ E muito mais". E também no próprio título do Programa: "Olhares Imaginando o Brasil".

A segunda questão que iremos levantar em relação à temática dos documentários produzidos no DOCTV é a possível influência que a presença do Estado - como agente fomentador do Programa - pode gerar na escolha das temáticas. Como já dissemos anteriormente, o DOCTV pretende revelar a diversidade cultural do país. Seus filmes apresentam uma forte tendência à busca de origens, busca das "raízes brasileiras" tentando valorizar a cultura popular. Em todo o processo de seleção, produção e distribuição dos documentários, em nenhum momento existe uma influência direta da representação do Estado na execução do filme. Mas, através da breve análise das temáticas majoritárias, notamos que os documentários sempre procuram responder a essa prerrogativa do Estado de criar uma identidade nacional. Assim ficam as questões: o fato do Programa ser dependente do apoio estatal influencia na escolha do tema pelos realizadores e pela comissão de seleção? 
Seria selecionado um documentário que argumentasse contra essa proposta?

\section{Ações do Minc para a TV aberta e pública}

A partir de 2003, o Minc passou a desenvolver ações voltadas para a televisão aberta e para televisão pública. Tais ações eram norteadas pela criação e aplicação de novos modelos de negócios que se adequassem melhor ao cenário audiovisual do período. As ações desenvolvidas em parceria com a TV pública criaram políticas de fomento à produção independente nas diversas regiões do país, integrada à teledifusão nacional em rede. Dentro desse contexto, foram criadas ações como o DOCTV nacional, o DOCTV Ibero América, Revelando os Brasis, Documenta Brasil, Banco de Documentários da América Latina, Programadora Brasil, entre outros.

Entre essas ações a mais próxima do modelo empregado no DOCTV é o Programa Documenta Brasil, produzido pela Associação Brasileira de Produtoras Independentes de Televisão (ABPI-TV) em parceria com o Sistema Brasileiro de Televisão (SBT), com o apoio da SAV/Minc, e o patrocínio da Petrobrás. O concurso Documenta Brasil visa apoiar a produção e lançamento de obras audiovisuais inéditas do gênero documentário e também é destinado às empresas audiovisuais brasileiras de produção independente.

Através da implantação da Empresa Brasil de Comunicação (EBC), operadora da TV Brasil, foi possível montar as bases de uma rede pública de TV envolvendo todos os Estados. O circuito nacional de teledifusão articulado pelo DOCTV é composto pelas seguintes emissoras: TV Aldeia do Acre, TV Educativa do Maranhão, TV Antares do Piauí, TV Ceará, TV Universitária do Rio Grande do Norte, TV Universitária da Paraíba, TV Cultura do Amazonas, TV Universitária de Roraima, TV Cultura do Pará, TV Palmas, TV Universitária de Pernambuco, TV Brasil Central de Goiás, TV Mais do Mato Grasso, TV Educativa Regional Mato Grosso do Sul, Rede Minas, TV Educativa do Espírito Santo, TV Educativa Brasil do Rio de Janeiro, Instituto Zumbi dos Palmares de Alagoas, TV Aperipê do Sergipe, TV Educativa da Bahia, Radiobrás, TV Cultura de São Paulo, Paraná Educativa, TV Cultura de Santa Catarina e TV Educativa do Rio Grande do Sul. Devido à inexistência de TVs públicas nos estados do Amapá e Rondônia, a Fundação Estadual de Cultura do Amapá e a Fundação Cultural Iaripuna, respectivamente, realizam estratégias alternativas de difusão do DOCTV em Rede Pública de Televisão.

\section{Conclusão}

Nesse ano de 2008, foi firmado novamente o convênio do Programa DOCTV para fomentar a sua quarta edição. Nessa nova edição mudam algumas diretrizes. A distribuição dos direitos patrimoniais sobre o documentário passou a ser igualitária: $25 \%$ para o autor, $25 \%$ para a produtora, $25 \%$ para o Fundo DOCTV e $25 \%$ TV Pública. O valor do contrato de co-produção também subiu para 110 mil reais, e o DOCTV constituirá a programação da TV Brasil, dentro do quadro de filmes para televisão.

O DOCTV não realiza integralmente todos os objetivos propostos, esbarrando em obstáculos como a fraqueza da Rede Pública de TV (que, em alguns estados, é representada por emissoras sem infra-estrutura e baixa audiência) e os atrasos na liberação das parcelas da verba. Na proposta do DOCTV, é clara a vontade política de construir um projeto alternativo de televisão brasileira que possibilite uma maior abertura à produção independente de documentários. 


\section{Bibliografia:}

BARNOUW, E. Documentary - a History of the Non-Fiction Film. Oxford: Oxford University Press, 1993.

BARSAM, R. Non-fiction Film Theory and Criticism. E.P.: Dutton, 1975.

BATISTA, M. "Documento Especial - entre a reportagem e o documentário". Revista de Cinema. São Paulo, Unesp, no. 6, 2001.

BERNARDET, J. C. Cineastas e imagens do povo. São Paulo: Brasiliense, 1985.

. Cinema brasileiro: propostas para uma história. Rio de Janeiro: Paz e Terra, 1979.

. Brasil em tempo de cinema - Ensaios sobre o cinema brasileiro. Rio de Janeiro: Paz e Terra, 1978.

CARROLL, N. "Ficção, não-ficção e o cinema da asserção pressuposta: uma análise conceitual". In:

RAMOS, F. P. Teoria contemporânea do cinema: documentário e narratividade ficcional. São Paulo: Senac, 2005.

CAVALCANTI, A. Filme e realidade. São Paulo: Martins, 1953.

CINEMAIS. Editorial. Rio de Janeiro, nº 8, novembro-dezembro de 1997.

CINEMAIS. Editorial. Rio de Janeiro, nº 36, janeiro-fevereiro de 2004.

DA-RIN, S. Espelho partido - tradição e transformação do documentário. Rio de Janeiro: Azougue, 2004. 1997. . “Auto-reflexividade no documentário". Rio de Janeiro: Cinemais, nº 8, novembro-dezembro de

EVANS, G. John Grierson and the National Film Board - the Politics of Wartime Propaganda. Toronto: University of Toronto Press, 1984.

GODOY, H. Documentário, realidade e semiose: os sistemas audiovisuais como fontes de conhecimento. São Paulo: Annablume, 2001.

GONÇALVES, G. S. “Panorama do documentário no Brasil”. In: DOC Online.

HARDY, F. (org.). Grierson on Documentary. Londres: Faber and Faber, 1979.

JACOBS, L. The Documentary Tradition. Londres: Norton \& Company, 1979.

LABAKI, A. \& MOURÃO, M. D. (org.). O cinema do real. São Paulo: Cosac \& Naify, 2005.

LINS, C. O documentário de Eduardo Coutinho - Televisão, cinema e vídeo. Rio de Janeiro: Jorge Zahar, 
2004.

MICHELSON, A. Kino-Eye - the Writings of Dziga Vertov. Berkeley: University of California Press, 1984.

NICHOLS, B. Introdução ao documentário. Campinas: Papirus, 2005.

. Representing Reality. Indianópolis: Indiana University Press, 1991.

. “A voz do documentário". In: RAMOS, F. P. Teoria contemporânea do cinema: documentário e narratividade ficcional. São Paulo: Senac, 2005.

ODIN, R. “A questão do público: uma abordagem semiopragmática”. In: Ramos, F. P. Teoria contemporânea do cinema: documentário e narratividade ficcional. São Paulo: Senac, 2005.

PONECH, T. What is Non-Fiction Cinema? On the Very Idea of Motion Picture Communication. Oxford: Westview Press, 1999.

RAMOS, F. P. "O que é documentário". In: RAMOS, F. P. et al. Estudos de Cinema Socine 2000. Porto Alegre: Sulinas, 2001.

. Teoria contemporânea do cinema: documentário e narratividade ficcional. São Paulo: Senac, 2005.

2003. . “Humberto Mauro”. In: Paranaguá, P. A. Cine documental em América Latina. Madrid: Cátedra,

RAMOS, F. P. \& MIRANDA, L. F. (orgs.) "Documentário mudo", "Documentário sonoro" e "Embrafilme". In: Enciclopédia do cinema brasileiro. São Paulo: Senac, 2003.

. "A cicatriz da tomada: documentário, ética e imagem intensa". In: RAMOS, F. P. Teoria contemporânea do cinema: documentário e narratividade ficcional. São Paulo: Senac, 2005.

RENOV, M. (org.) Theorizing Documentary. Nova York: Routledge, 1993.

RENOV, M. \& GAINES, J. Collecting Visible Evidence. Minneapolis: University of Minnesota Press, 1999.

ROTHMAN, W. Documentary Film Classics. Nova York: Cambridge University Press, 1997.

SCHVARZMAN, S. Humberto Mauro e as imagens do Brasil. São Paulo: Unesp, 2004.

SONTAG, S. Diante da dor dos outros. São Paulo: Companhia das Letras, 2004.

TEIXEIRA, F. E. (org). Documentário no Brasil - tradição e transformação. São Paulo: Summus, 2004.

. "Enunciação no documentário: o problema de 'dar a voz ao outro"”. In: FABRIS, M. et al. (orgs.). Estudos de Cinema Scoine. Porto Alegre: Sulina, 2003.

WINSTON, B. “The Documentary Film as Scientific Inscription”. In: RENOV, M. (org.). Theorizing Documentary. Nova York: Routledge, 1993. 
Webgrafia:

Site oficial do DOCTV: http://www.tvcultura.com.br/doctv

Site do Minc: http://www.cultura.gov.br

Site da Associação Brasileira de TVs Públicas, Educativas e Culturais (ABEPEC): http://www.abepec.com.br Site da Agenda DOCTV:

http://www.google.com/calendar/embed?src=tvt5kae0vlk8o42mi18aokbaio\%40group.calendar.google.com Site do Porta-arquivos DOCTV: http://www.4shared.com/dir/851862/54696c2d/sharing.html Site da Associação Brasileira dos Documentaristas (ABD): http://www.abdnacional.org.br Sites das TVs públicas e educativas participantes da Rede DOCTV:

TVU RR: http://www.ufrr.br

FUNDECAP: http://www.amapa.gov.br

TVC AM: http://www.doctvamazonas.ubbihp.com.br

TVC PA: http://www.portalcultura.com.br

TV PALMAS: http://www.redesat-to.com.br

TV ALDEIA: http://www.ac.gov.br

Fundação Iaripuna: http://www.portovelho.ro.gov.br

TVE MA: http://www.redebrasil.tv.br

TV Antares: http://www.pi.gov.br

TV Ceará: http://www.tvceara.ce.gov.br

TVU RN:http://www.tvu.ufrn.br

TVU PB:http://www.ufpb.br

TVU PE: http://www.ufpe.br/tvu

IZP: http://www.tveducativa-al.com.br

TV Aperipê: http://www.aperipe.com.br

TVE BA: http://www.irdeb.ba.gov.br 
Radiobrás: http://www.radiobras.gov.br

TV Brasil Central: http://www.agecom.go.gov.br

TV Mais MT: http://www.amav.org.br / www.unic.br

TVE Regional MS: http://www.tveregional.com.br/index

Rede Minas: http://www.redeminas.mg.gov.br

TVE ES: http://www.es.gov.br

TVE Brasil: http://www.redebrasil.tv.br

TV Cultura: http://www.tvcultura.com.br

TVE PR: http://www.pr.gov.br/rtve

TVC SC: http://www.tvcultura.ufsc.br

TVE RS: http://www.tve.com.br

\section{Mini Currículo :}

Mestranda do Programa de Pós-Graduação em Multimeios da Unicamp. 